\title{
Facilitating Meaningfulness in the Workplace: A Field Intervention Study
}

\begin{abstract}
This paper presents the findings of a field intervention study that sought to address two objectives: a) what are the psychological effects of a meaningfulness intervention? and b) what key issues should be considered when developing meaningfulness interventions? Eighty employees from three different organizations based in the UK were allocated to either the intervention condition or a wait-list control group. Compared against the waitlist control group, the meaningfulness intervention facilitated meaningfulness in/at work, job/organization engagement, and personal initiative. Finally, focus group interviews revealed a number of micro (e.g., sustaining motivation), meso (e.g., role of line managers), and macro (e.g., socio-political events) level issues that should be considered when planning and implementing meaningfulness interventions. Overall this study makes use of field intervention research in order to develop the rationale for incorporating meaningfulness theories and concepts within HRM practice, particularly in better aligning personal development, team-based learning, and performance management activities.
\end{abstract}

Keywords: field intervention; mixed methods; meaningful work; employee engagement; personal initiative

\section{Introduction}

The concept of meaningfulness as a 'fundamental' psychological need that strengthens an individual's self-worth and personal agency (Kahn \& Heaphy, 2014; Saks, 2011; Yeoman, 2014) is becoming increasingly relevant to human resource management (HRM) scholars and practitioners (Bailey, Yeoman, Madden, Thompson, \& Kerridge, 2018; Lysova, Allan, Dik, Duffy, \& Steger, 2018). This is perhaps due in part to its fragility and complexity within contemporary workplaces, such that there is rising concern that employers are potentially eroding meaningfulness and, in consequence, jeopardizing the fulfilment of human potential 
(Bailey, Madden, Alfes, Shantz, \& Soane, 2017). Even occupations and organizations which have previously been viewed as providing objectively 'meaningful' jobs are facing challenges, such as increasing uncertainty and rising demands, given the backdrop of the global recession (e.g., Wood \& Ogbonnaya, 2016) and neoliberal political and economic agendas (e.g., Dempsey \& Sanders, 2010). Although there are different perspectives and terminology surrounding meaningfulness within the workplace, this study focuses on meaningfulness as a subjective individual-level experience that arises when a person perceives their work to be significant and valuable, to themselves personally and to others in the organization (Pratt \& Ashforth, 2003). Moreover, we acknowledge that meaningfulness is shaped by the individual's sense of who they are and their wider lives (Chalofsky \& Krishna, 2009; LipsWiersma \& Morris, 2009).

Despite some questionnaire studies showing that meaningfulness may be particularly strengthened by providing opportunities for learning and personal development (Bailey et al., 2018; Fletcher, 2016), little is known about the potential impact of implementing such HRrelated interventions. This issue is also pertinent given that there is growing evidence within HRM research that meaningfulness is an important antecedent of engagement (e.g., Fletcher, Bailey, and Gilman, 2018; Soane et al., 2013) and its associated behavioral manifestations, such as personal initiative (Hakanen, Perhoniemi, \& Toppinen-Tanner, 2008). Furthermore, although there has been a rise in popularity of the concept of employee engagement and associated HRM strategies to 'engage' staff, there are potential limitations to how effective HRM may be in enacting these strategies in ways the authentically facilitate meaningfulness and engagement (Arrowsmith \& Parker, 2013; Truss, Shantz, Soane, Alfes, \& Delbridge, 2013; Lips-Wiersma \& Morris, 2009). Therefore, there is a need to understand how practitioners could utilize meaningfulness interventions as a way to facilitate engagement and its behavioral manifestations within their workplaces. Given this need, it is surprising that 
intervention or experimental studies on meaningfulness are woefully lacking, yet there is promise from an emerging strand of research that suggests that conducting such interventions is a fruitful avenue for HRM research and practice (Bailey et al., 2018; Lysova et al., 2018).

In light of the above, the purpose of the current study is to better understand how meaningfulness can be facilitated through a workplace intervention, and in doing so it seeks to achieve two main objectives: 1) what are the psychological effects of the meaningfulness intervention?, and 2) what key issues should be considered when developing meaningfulness interventions?.

The first objective focuses on clarifying how a meaningfulness intervention can facilitate engagement and its behavioral outcomes within the workplace. More specifically. we aim to test the specific effects of a meaningfulness intervention against a wait-list control group. It is hypothesized that the intervention will, relative to the control group, facilitate meaningfulness, engagement, and personal initiative. This is based on the rationale that meaningfulness broadens opportunities for the individual to invest their self in full role performance, and as such 'fully engage' (Fletcher et al., 2018; Kahn, 1990; Soane et al., 2013), and triggers motivational processes that encourages volitional purposeful behavior, such as personal initiative (Barrick, Mount, \& Li, 2013; Hakanen et al., 2008).

The second objective attempts to better understand the pragmatic reality of designing and implementing meaningfulness interventions by exploring the contextual 'process' factors that may facilitate or undermine the success of the intervention (Nielsen, Taris, \& Cox, 2013). In doing so, it embeds the theoretical foundations of meaningfulness research within the practitioner context and brings to light contextual factors that might need to be incorporated within theories and models of meaningfulness (Johns, 2006). 


\section{Theoretical Framework}

\section{The concept of meaningfulness}

Although the term meaningfulness is often used alongside other terms such as meaning, callings, and job crafting, the experience of meaningfulness is a distinct psychological experience that signifies the perceived amount of significance attached to work (Rosso, Dekas, \& Wrzesniewski, 2010). These perceptions of significance and value can be seen as deriving from one's job role as well as one's membership to an organization (Pratt \& Ashforth, 2003). This duality stems from social identity theory (Tajfel \& Turner, 1979) and role theory (Katz \& Kahn, 1978) which emphasize one's identity as a member of an organization and the influence of one's work role, respectively. These therefore give rise to two inter-related, yet distinct forms of meaningfulness (Pratt \& Ashforth, 2003; Saks, 2011).

The first form, meaningfulness in work, constitutes a subjective assessment of 'the value of the task goal or purpose, judged to the individual's own ideals of standards' (Thomas \& Velthouse, 1990, p.672). This concept has been the focus of work psychology researchers due to its position within the widely known job characteristics model (Hackman \& Oldham, 1976). Thus, the experience of meaningfulness in work arises primarily through the design and perceived fit of one's job role, as well as rewarding social interactions experienced during the performance of one's work role (Kahn, 1990).

The second form, meaningfulness at work, reflects a subjective assessment of 'where do I belong?' and so is the extent to which one views one's work as enhancing one's membership and connection with the organization (Pratt \& Ashforth, 2003). This concept may represent an important psychological process that underpins social identification with the organization and its members (Cohen-Meitar, Carmeli, \& Waldman, 2009; Tajfel \& Turner, 1979). Thus, the experience of meaningfulness at work is facilitated by building 
strong organizational cultures and identities, and through transformational and visionary leadership (Pratt \& Ashforth, 2003).

Although these two constructs do not fully encompass the conceptual space of meaningfulness (Bailey et al., 2018), they do reflect an interconnection between one's identity, aspirations and work attachments (Rosso et al., 2010). As such, meaningfulness, as represented by meaningfulness in and at work, not only imbues work tasks with a sense of purpose and value, but also affirms one's membership to the organization and helps to connect the individual with the wider beneficiaries of their work, such as customers (Kahn \& Heaphy, 2014; Pratt \& Ashforth, 2003; Saks, 2011). This sense of coherence between the individual, their work, and the organization is also emphasized by other scholars. For example, Lips-Wiersma \& Morris (2009) delineate four core sources of meaningful work, that when coherently aligned provide the strongest sense of fulfilment.

\section{Meaningfulness as a critical psychological state}

Meaningfulness has long been considered as a critical psychological experience, necessary for high levels of motivation, satisfaction and performance, because it is a fundamental psychological need that strengthens an individual's self-worth and life experience (Rosso, et al., 2010; Yeoman, 2014). More specifically, when an individual experiences meaningfulness they are internally driven to act in ways that fulfil their future work goals in line with their values for self-enhancement and self-transcendence as well as their psychological needs for relatedness and belonging (Glazer, Kozusznik, Meyers, \& Ganai, 2014). As such, meaningfulness may broaden affective and cognitive processes that promote a wider interest in the work context, for example work goals and expected performance behavior, and build personal resources, such as self-efficacy, that enable intrinsically motivated behavior to occur (Barrick, Mount, \& Li, 2013; Fletcher et al., 2013; Soane et al., 2013). 
In doing so, the experience of meaningfulness allows energy to be replenished, refocuses efforts towards achieving goals, and enables authentic self-expression at work (Chalofsky \& Krishna, 2009; Kahn, 1990; May, Gilson, \& Harter, 2004). Therefore, the individual will feel willing and motivated to 'express and employ' their 'preferred self' in a connected and focused way within their role performances (Kahn, 1990) such that it manifests as 'engagement'. This state of engagement reflects the simultaneous expression of emotional (e.g., feeling enthusiastic and excited), cognitive (e.g., focusing attention and stimulating one's intellect), and physical/social (e.g., expending effort and energy, socially connected to and interacting with colleagues) dimensions within their roles.

Although most research on engagement focuses on engagement within the job or work role (Truss et al., 2013), it could also be argued, drawing on the earlier discussion on meaningfulness in/at work (Pratt \& Ashforth, 2003), that engagement, similar to meaningfulness, consists of two distinct, yet related types based on the distinction between one's work role and role as an organizational member. Thus, in this study, we draw upon Saks's (2006) distinction between job engagement and organization engagement whereby the former reflects the extent to which an individual is 'psychologically present' in their job role whereas the latter signifies the extent to which an individual is 'psychologically present' in their role as a member of the organization. Moreover, some scholars have highlighted the need to reframe engagement within the context of meaningful work in order to sustain and nurture engagement across a wide range of tasks and situations that benefits both the employee and the employer. For example, Shuck and Rose (2013) propose a framework through which engagement is interpreted via three core areas of meaningful work: personal contribution, personal influence, and personal reward.

Given that meaningfulness is proximal to the experience of engagement (Kahn, 1990; May et al., 2004) it is therefore also likely to influence behavioral manifestations or outcomes 
of engagement. More specifically, engaged individuals will be more willing to take risks and invest their own resources into a) trying out new ideas and actions, b) exploring and taking advantage of opportunities to grow and develop, and c) finding their own solutions to problems (Hakanen et al., 2008). These types of behaviors can be classified as personal initiative - 'a behavior syndrome resulting in an individual's taking an active and self-starting approach to work and going beyond what is formally required' (Frese, Fay, Hilburger, Leng, \& Tag, 1997, p.140). Drawing on the theory of purposeful work behavior (Barrick et al., 2013), meaningfulness is therefore likely to elicit high levels of personal initiative because they direct purpose and attention towards enacting volitional behaviors that fulfil the individual's needs for affiliation and autonomy. Indeed, there is some evidence that meaningfulness stimulates such behaviors, for example those associated with creativity (Cohen-Meitar et al., 2009).

\section{Meaningfulness interventions}

Traditional psychological-related interventions tend to focus on the negative aspects of work that cause stress and poor health/wellbeing (Nielsen \& Randall, 2013). Although these are very important and necessary, such approaches tend to neglect the more positive and fulfilling aspects of work that contribute to optimal psychological functioning, and so focusing on meaningfulness may represent a unique complementary approach that augments these traditional interventions (Nielsen et al., 2010). Despite previous questionnaire studies indicating the potential value of developmental HRM practices for facilitating meaningfulness and its outcomes (e.g., Fletcher, 2016), there remains a lack of a coherent and cohesive set of practical interventions that are grounded in robust theory or an evidencebased approach (Bailey et al., 2018). Recently there have been a small number of experimental/intervention studies that have shed light on how organizations may be able to facilitate meaningfulness in the workplace. For example, across three experiments, Allan, 
Duffy, and Collisson (2018) found that when individuals focus on helping others they tend to perceive their work as more meaningful. A few other studies have included aspects of meaningfulness within broader empowerment (Voetgtlin, Boehm, \& Bruch, 2015) or psychological capital (Costantini et al., 2017) interventions, and Thory (2016) revealed, through interpreting qualitative interview and participant observation data, emotional intelligence training can enable managers to identify and actively pursue elements of their work role that are the most fulfilling, authentic, and self-actualizing.

Collectively these studies show promise for developing a meaningfulness-specific personal development intervention that HR managers can implement. Importantly our meaningfulness intervention builds upon these existing studies by focusing on core elements that draw upon Pratt and Ashforth's (2003) theorizing of meaningfulness in and at work. More specifically, we incorporated discussions and reflective/goals setting activities within the intervention on the following areas of meaningfulness in work: a) work design and elements of autonomy and job crafting that foster meaningfulness, b) most meaningful learning and personal growth work activities/events, and c) involvement and related practices that allow one to express one's personal values/goals and knowledge in meaningful ways; and meaningfulness at work: a) how one's work is validated and affirmed as being valued by beneficiaries and the organization, b) opportunities to develop a deeper sense of shared purpose and culture; and c) role of managers and wider organizational practices that create a meaningful sense of belonging, trust, and community. These elements also reflect broader models, such as Lips-Wiersma's (2009) four sources that foster meaningful work: developing one's self, expressing full potential, unity with others, and serving others; as well as literature that connects meaningfulness with engagement (e.g., Kahn, 1990; Kahn \& Heaphy, 2014; Soane et al., 2013). Overall, our intervention focuses specifically on meaningfulness by developing self-awareness and self-reflection of what is meaningful to one's self and to 
others, deepening the purpose of one's role and sense of identity with the organization, and strengthening social bonds and work relationships to build a shared sense of meaningfulness. In order to achieve our first objective regarding the proposed effects of the intervention, we set out three hypotheses.

First, it is expected that the meaningfulness intervention will increase levels of meaningfulness in and at work over the study period, compared with those in the wait-list control condition. This is because the intervention will draw participants' attention towards the benefits of taking opportunities within the workplace that enable them to experience a sense of meaningfulness, thus increasing the salience of resource gain (Hobfoll, 2011). In this sense, the intervention will promote investment of internal psychological resources into activities that enables them to experience heightened levels of meaningfulness, thus reflecting an accumulation process of resource gain (Hobfoll, 2011).

Hypothesis 1: Compared with the control condition, the meaningfulness intervention will significantly increase meaningfulness in and at work.

Second, it is hypothesized that the meaningfulness intervention will raise engagement levels relative to the wait-list control condition because it is likely that an intervention that seeks to raise meaningfulness will also promote engagement through broadening perceived opportunities for engagement and building key personal resources needed to engage (Fletcher et al., 2018; Soane et al., 2013). Meaningfulness is necessary for engagement because such experiences allow energy to be replenished, refocus efforts towards achieving goals, and enable authentic self-expression at work (Chalofsky \& Krishna, 2009) in ways that promote investment of the self within the full performance of one's work role (Kahn, 1990) and role as an organizational member (Saks, 2006). 
Hypothesis 2: Compared with the control condition, the meaningfulness intervention will significantly increase a) job engagement and b) organization engagement.

Lastly, it is predicted that the meaningfulness intervention will facilitate personal initiative relative to the wait-list control condition. Drawing on the theory of purposeful work behavior (Barrick et al., 2013), the intervention will strengthen participants' purposeful goal striving in ways that focus upon facilitating their sense of meaningfulness which in turn will trigger volitional task-specific motivational processes that lead to personal initiative behaviour being enacted (Frese et al., 1997). As the context of the intervention will be concordant with the individual's needs for affiliation and autonomy (Barrick et al., 2013), it is likely that the individual will feel intrinsically motivated to behave in more proactive ways.

Hypothesis 3: Compared with the control condition, the meaningfulness intervention will significantly increase personal initiative.

\section{Optimizing meaningfulness interventions for the future}

Our second objective is to identify and explore key issues that should be considered when developing meaningfulness interventions within the workplace. It is important to understand how the design and implementation of meaningfulness interventions can be best optimized, particularly as the meaningfulness literature has 'been relatively silent on how employees may respond to organizational initiatives geared towards raising their levels of experienced meaningfulness' (Bailey et al., 2017, p.421). This connects with the wider literature on organizational interventions that argues that there is a fundamental need to open the 'black box' to identify the processes (i.e. the 'how') and reasons (i.e., the 'why') underlying the outcomes of an intervention (e.g., Nielsen \& Abildgaard, 2013; Nielsen \& Randall, 2013). Importantly, by analyzing the contextual factors surrounding the implementation of an intervention, particularly across different settings, researchers can better transfer their 
knowledge and evidence of 'what works' to practice and better ensure ecological validity (Nielsen \& Randall, 2013; Nielsen, Taris, \& Cox, 2013).

Moreover, it is useful that field intervention research studies consider participants' experiences of the study as employees are often, in reality, active 'crafters' of intervention content and process (Nielsen, 2013). Indeed, research (e.g., Abildgaard, Saksvik, \& Nielsen, 2016) has shown the value of exploring participants' experiences for understanding the individual and contextual factors that might hinder or strengthen the impact of an intervention. Considering that the important influence of context on psychological states and behavior is often neglected (Johns, 2006), this will therefore help provide insight into the pragmatic reality of facilitating meaningfulness and potential contextual factors that need to be incorporated within theory.

Lastly, scholars have also raised the concern that approaches to 'managing' meaningfulness within the workplace may have a darker side that leads to 'existential labor' and exploitation if conducted in inauthentic or mandated ways (Bailey et al., 2017; LipsWiersma \& Morris, 2009). Given that HR and line managers would, ideally, have a role in designing and implementing meaningfulness interventions, it is also important to identify specific managerial capabilities, resources, policies, and support that can help prevent the intervention from becoming inauthentic or exploitative.

\section{Method}

\section{Research sites and sampling strategy}

Although not explicitly adopting a case study methodology, the logic underlying the selection of 'cases' is still relevant because the study aims to generalize as well as compare the experience of the intervention. Yin (2009) presents two forms of replication logic that can be used as guiding principles: theoretical (i.e. cases produce contrasting results for predictable 
reasons) or literal (i.e. cases predict similar results). Firstly, applying the theoretical logic, three types of organization that differ in terms of occupational composition and sector were selected so we could see how the intervention would be experienced across settings with differing underpinning values, motives, and foci in terms of what might be deemed particularly meaningful. For example, employees in the public sector are likely to be more focused on elements related to doing one's public duty and compassion than those in the private sector (e.g., Vigoda-Gadot, Eldor, \& Schohat, 2013). Secondly, applying the literal logic, we sought out similarly sized organizations that had explicit employee engagement strategies and had used staff surveys to identify workgroups at risk of disengagement.

Therefore, the study took place in three different UK organizations: Public Co - a large non-ministerial department of the UK Government based in Central London that offers specialist services primarily to other UK Government departments; Engineering Co - a large multinational company within the defence and security sector, whereby the main UK site is based in the South of England and is focused on engineering and software functions; and Financial Co - a large financial mutual based in the Midlands in the UK, specializing in providing financial services to a range of professions and SMEs. The recruitment of participants from each organization focused on work units that had been highlighted by senior managers/the HRM function as being less engaged than other work units (based on annual employee engagement surveys) and as experiencing threats to their identity within the organization, such de-skilling of roles and increasing routinization. While armed with evidence that there were issues with employee engagement, the HRM functions in these organizations were not equipped to deliver the intervention in-house although were keen to explore this research collaboration in order to improve their practice. To maintain the independence of the research, the HRM function did not get directly involved in the data collection or analytical processes. 


\section{Intervention design and procedure}

A field intervention design was undertaken which focused on comparing an intervention group with a wait-list control group. Participants in the two conditions undertook the three online questionnaires at the same time: T1 at week 1, T2 at weeks 8 to $10, \mathrm{~T} 3$ at weeks 12 to 14. The wait-list control group participated in the intervention activities after the study was completed and were asked to complete the baseline (T1) as well as end (T2 and T3) online questionnaires only during the study period. The meaningfulness intervention group received a two-hour training session followed by weekly individual activities for a total of four weeks. The intervention was undertaken within each research site separately and at different time points: from January to March 2016 in Public Co, from April to June 2016 in Engineering Co, and from January to March 2018 in Financial Co.

In the training session participants undertook a series of small group (four person) discussions, facilitated by the researchers, on the different sources of meaningfulness drawing on Pratt and Ashforth's (2003) theorizing: meaningfulness derived from yourself and your family; from the work itself; and from the workplace. As Rosso et al's (2010) review and other scholars point out (e.g., Chalofsky \& Krishna, 2009; Lips Wiersma \& Morris, 2009), meaningfulness is also shaped by the individual's sense of who they are and what values/beliefs are important to them as well as their wider lives outside of work. Therefore, we opened the training with a discussion on what each person deemed most important in terms of their wider sense of meaningfulness before focusing on what was meaningful from work/workplace. This also helped to reduce the potential 'management' or 'coercion' of their meaning-making (Lips Wiersma \& Morris, 2009). The small groups then came together (around 12 to 16 participants in each research site) to discuss key similarities and differences in terms of what was meaningful to them within the context of their work, workplace, and organization. The final part of the session focused on explaining the weekly activities. 
At the start of each of the following four weeks after the training session, participants received an email with the word document attachment whereby they were instructed to allocate time towards the end of each week to work through three activities and to send back their completed activity document by the start of the following week. The three discrete activities were grounded from scholarly work connecting meaningfulness with engagement (e.g., Kahn, 1990; Kahn \& Heaphy, 2014; Soane et al., 2013); with each activity lasting 10 to 15 minutes per week: a) reflecting upon a relatively meaningful event/situation that happened at work; b) discussing how a broader source of meaningfulness could be utilized/strengthened within the workplace; and c) reflecting on and setting a behavioral goal they feel would have a meaningful impact within their workplace (they were also asked to evaluate the meaningful goal they had set themselves the previous week).

\section{Allocation of conditions}

Participants were randomly allocated to one of the conditions; however, this was not the case for some participants due to changes in individual work schedules, or where it made sense to keep those that worked closely together in the same condition, i.e. to reduce crossover/confounding effects between the two conditions. A total of 80 employees ( 24 from Public Co, 28 from Engineering Co; 28 from Financial Co) participants were allocated to either the wait-list control $(n=35)$ or the first phase intervention group $(n=45)$.

The mean age of participants was 44.01 years (SD 11.25) and 56 per cent were male. Around a third had supervisory or managerial responsibility, and 95 per cent were on fulltime contracts. However, participants from Engineering Co were significantly older than those from Public Co and Financial Co ( $M=49.04$ vs. 40.00 vs. 42.43 years). Moreover, the majority from Engineering Co and Financial Co were male compared with a majority female sample from Public Co (75 per cent vs. 61 per cent vs. 25 per cent male). These differences parallel the main workforce differences between the organizations. 


\section{Data collection activities}

In line with recommendations from the wider organizational interventions literature (e.g.,

Nielsen et al., 2010; Abildgaard et al., 2016), we adopted a mixed methods research design in order to capture data regarding the outcomes (i.e., quantitative data) as well as the process (i.e., qualitative data) of the intervention.

\section{Quantitative data collection}

The baseline (T1) questionnaire captured core self-evaluations, job, and demographic details as well as the before study levels of the dependent variables. The end survey 1 (T2) questionnaire captured after study levels of the dependent variables, except personal initiative. The end survey 2 (T3) questionnaire captured after study levels of personal initiative, which was assessed a few weeks after T2 as changes in behavior will likely occur after changes in psychological states. All measures unless otherwise stated used a seven-point Likert scale ( 1 - strongly disagree to 7-strongly agree). Items, apart from the control variables, were modified to direct attention towards how the respondent felt over the past month e.g., 'Over the past month, the work I did on this job was very important to me'. This was to help ensure temporal separation between the study period measurements.

Meaningfulness in work. Meaningfulness in work was assessed before (T1) and after (T2) the intervention period using May et al.'s (2004) 6-item meaningfulness scale, which focuses on the perceived significance, worth, and importance of the work role to one's self, e.g., 'The work I do on this job is very important to me'. The inter-item reliability was $\alpha=.92$ at T1 and .95 at $\mathrm{T} 2$.

Meaningfulness at work. Meaningfulness at work was assessed before (T1) and after (T2) the intervention period. As there were no validated measures of meaningfulness at work at the time of the study, the author developed three items based on Pratt and Ashforth's (2003) and 
Saks's (2011) definitions, which focus on the perceived significance, impact and value of one's work role to the organization and its beneficiaries: 'My work is deemed valuable by the organization', 'My work contributes to the success of the organization', 'Through my work I have made a positive difference to customers/clients/service users'. The inter-item reliability was $\alpha=.83$ at $\mathrm{T} 1$ and .82 at $\mathrm{T} 2$.

Job engagement. Job engagement was captured using Soane et al.'s (2012) 9-item ISA engagement scale before (T1) and after (T2) the intervention period. This scale assesses three dimensions of engagement drawing on Kahn's (1990) conceptualization of personal role engagement: a) intellectual, e.g. 'I focus hard on my work'; b) social, e.g., 'I share the same work values as my colleagues'; and c) affective, e.g. 'I am enthusiastic in my work'. The inter-item reliability was $\alpha=.90$ at $\mathrm{T} 1$ and .88 at $\mathrm{T} 2$.

Organization engagement. Saks's (2006) six-item organization engagement scale were used to assess the individual's engagement with their role as an organizational member before (T1) and after (T2) the intervention period, e.g., 'Being a member of this organization is exhilarating for me'. The inter-item reliability was $\alpha=.91$ at T1 and .91 at T2.

Personal initiative. Personal initiative was assessed before (T1) and four weeks after (T3) the intervention period using Frese et al.'s (1997) seven-item personal initiative scale. An example item is 'I actively attack problems'. The inter-item reliability was $\alpha=.86$ at T1 and .88 at $\mathrm{T} 3$.

Control variables. Prior studies have shown that individuals differ in their dispositional tendencies for personal agency (Chang, Ferris, Johnson, Rosen, \& Tan, 2012). To control for the potential confounding effect of these individual differences, Judge, Erez, Bono, \& Thoresen's (2003) 12-item core self-evaluations (CSE) measure was used (e.g., 'I determine what will happen in my life'); higher scores indicate a positive self-concept associated with 
high levels of personal agency. The inter-item reliability for CSE was $\alpha=.90$. As the samples were drawn from three different organizations, two dummy variables were created to control for the potential impact of the organization.

\section{Qualitative data collection}

Qualitative data was collected from the meaningfulness intervention participants in two ways. First, a 45 minute semi-structured focus group interview was conducted at the end of the study period, which focused on better understanding participants' experiences of the meaningfulness activities, as well as their thoughts on how meaningfulness could be further developed and embedded within their organization. The interview guide is given as Appendix A. Second, within the T3 survey open-ended questions were asked regarding what aspects of the weekly activities they found useful and enjoyable as well as their thoughts about how to improve the usefulness and utilization of the weekly activities within the organization.

\section{Analytic strategy}

\section{Multilevel analysis}

As the quantitative data was hierarchically ordered at two levels: measurement occasion (pre/post study) clustered within the individual, multilevel modelling was conducted using MLwiN version 2.32 (Rashbash, Steele, Browne, \& Goldstein, 2015). The intraclass correlations of the dependent variables confirmed that multilevel modelling was appropriate as there were sufficient levels of variance at both levels: within-person variance ranged between $27.17 \%$ (job engagement) and 51.62\% (meaningfulness at work). Moreover, multilevel modelling is viewed as being superior to traditional ANOVA approaches when examining intervention effectiveness (Lischetzke, Reis, \& Arndt, 2015).

To test Hypotheses 1 to 3, cross-level interaction effects were calculated (i.e. time, as level 1 dichotomous predictor, $\mathrm{x}$ codition, as level 2 dichotomous moderator). Thus, for each 
dependent variable, two random intercept and random slope models were conducted using IGLS estimation - Model 1 - included co-variates, time, and condition; Model 2 - extended Model 1 by including the cross-level interaction between time and condition. Core selfevaluations was grand-mean centred in both models. The effect size focusing on the crosslevel interaction's explanatory power was calculated (i.e. percentage of the total variance in the time slope explained by the type of condition), and the significance of the simple slopes was tested for control and intervention conditions (Preacher, Curran, \& Bauer, 2006).

\section{Preliminary checks on quantitative data}

Attrition rates and missing data. Of the 80 individuals in the sample, 73 completed T2 measures, and 63 went on to complete the final T3 measure of personal initiative; representing a participation rate of 91 per cent at $\mathrm{T} 2$ and 79 per cent at $\mathrm{T} 3$. The use of multilevel analyses enables any missing data to be included and so the full dataset of the 80 participants was retained. Attrition rates were fairly equal across the three organizations yet were higher in the control condition at T3 (66 per cent of control participants completed all three time points compared with 89 per cent of intervention participants). Independent t-tests found no significant differences in the baseline measures nor in the demographic characteristics between the control and intervention participants; indicating that the allocation of participants did not result in any major biases. Moreover, a multivariate ANOVA on the five baseline dependent variables found no significant effect of a) condition: $F(5,72)=0.30$, $p=.91$; b) those missing data: $F(5,72)=0.14, p=.98$, and c) combination effect of condition and missing data: $F(5,72)=1.86, p=.11$. Therefore, we can be fairly confident that the analyses and results of the full dataset are robust.

Differentiating the dependent variables. To verify that the five dependent variables (meaningfulness in work, meaningfulness at work, job engagement, organization engagement, personal initiative) were distinct, a set of multilevel CFAs were conducted. All 
variables were represented by their items, except job engagement which was represented by its three constituent dimensions (intellectual, social, affective). Moreover, alternative nested models were tested to ensure that no other (more parsimonious) alternatives were suitable. Table 1 shows the results of the multilevel CFAs and shows that the five dependent variables were distinct from one another, as indicated by the five factor measurement model: $\chi^{2}(530)=$ 797.26, $p<.001 ; \chi^{2} / \mathrm{df}$ ratio $=1.50 ; \mathrm{RMSEA}=0.06 ; \mathrm{CFI}=0.89 ; \mathrm{SRMR}$ within $=0.10$

SRMR between $=0.14$. Although alternative models did not fit the data better, we acknowledge that the CFI and SRMR values are somewhat outside of acceptable boundaries, yet this may be partly attributed to the relatively small dataset.

Insert Table 1 about here

\section{Qualitative thematic analysis}

The qualitative data were triangulated along with observations and reflective notes of the researchers. The content from these sources was sifted for material that would help answer RQ2 and this material was then analyzed, using a general thematic analytic process (Braun \& Clarke, 2006), to identify key issues related to micro (individual-level), meso (business unit/organization-level), and macro (institutional/societal/sectoral level). A realist approach to qualitative analysis was undertaken to understand the contextual factors that participants viewed as impacting their perceptions, experiences, and potential success of the meaningfulness intervention, and of potential future meaningfulness initiatives within their organization. Braun and Clarke's (2006) six phases of thematic analysis were followed: 1) transcribing, (re)reading the data, and noting down initial ideas, 2) generating initial codes from identifying interesting features within the data, 3) collating codes and gathering data 
into potential themes, 4) reviewing themes and generating thematic map, 5) defining and naming themes, and 6) producing the final thematic report. One researcher undertook the full six phases and then this was reviewed by a second researcher to check that the themes and coded extracts reflected the full dataset.

\section{Results}

\section{Multilevel analysis}

Cross level interactions and effect sizes are taken from Table 2, which shows the results of the multilevel analyses, and Table 3 reports the outcomes of the simple slope analyses.

Hypothesis 1 was supported as there was a significant cross-level interaction for both meaningfulness in work $(\gamma=.39, p<.05)$ and meaningfulness at work $(\gamma=.70, p<.01)$. The effect sizes were fairly modest - the type of condition explained 4.69 percent of total variance in the time slope for meaningfulness in work and 11.67 percent for meaningfulness at work. The simple slope analyses revealed that the intervention group showed an increase over this time for meaningfulness in work $(z=2.75, p<.01)$ and a marginal increase for meaningfulness at work $(z=1.89, p=.06)$. In contrast, the control group did not experience any significant change before and after the study for meaningfulness in work $(z=0.09, p=$ .92), yet for meaningfulness at work the control group showed a significant decrease over the time period $(z=2.36, p<.05)$.

Hypothesis 2 was partially supported as the cross-level interaction was marginally significant for job engagement $(\gamma=.24, p=.09)$ and significant for organization engagement $(\gamma=.47, p<.05)$; with the type of condition explaining 3.53 percent of the total variance in the time slope for the former and 5.83 percent for the latter. The simple slopes analysis shows that the intervention group experienced marginally significant increases in job engagement $(z$ $=1.65, p=.10)$ and significant increases in organization engagement $(z=2.19, p<.05)$ over 
the time period, whereas the control group did not for job engagement $(z=0.89, p=.38)$ nor for organization engagement $(z=0.64, p=.52)$.

Lastly, Hypothesis 3 was supported as the cross-level interaction was significant for personal initiative $(\gamma=.47, p<.01)$; whereby 12.72 percent of the total variance in the time slope was explained by the type of condition. As indicated by the simple slopes analysis, the intervention group showed a significant increase in personal initiative over the time period $(z$ $=2.56, p=.01)$ whereas the control group exhibited a marginal decrease over the time period $(z=1.66, p=.10)$

Post-hoc tests were also undertaken to examine whether core self-evaluations may be a potentially influential individual difference that moderates the impact of the intervention. Three-way interactions (time $\mathrm{x}$ condition $\mathrm{x}$ CSE) were not found to be significant across any of the dependent variables: meaningfulness in work $(\gamma=-.35, p=.08)$, meaningfulness at work $(\gamma=-.38, p=.11)$, job engagement $(\gamma=-.18, p=.23)$, organization engagement $(\gamma=-$ $.34, p=.16)$, and personal initiative $(\gamma=-.08, p=.65)$.

\section{Qualitative analysis}

From the thematic analysis, the following issues were revealed: three emerged at the micro level - i.e. individual differences and psychological issues; four emerged at the meso-level i.e. workgroup/departmental, organizational and managerial issues; and one emerged at the macro-level - i.e. occupational, sectoral, and national issues. 
Gaining buy-in and overcoming initial scepticism: Some acknowledged that they were somewhat sceptical when they signed up to participate. This was also observed by the researchers; some participants were slightly cynical at the start of the study, for example one joked 'I thought you were here to tell us how to get more meaning from our work'. But as they engaged in the discussion and activities, most started to think more deeply and be more open to the idea of reflecting on what made their work more meaningful. Some participants expressed, within the focus group discussion, that some members of their team may have needed some more convincing if they were to participate: 'Some just won't engage and will just moan and complain'. These more cynical members were categorized as those who had been in the organization for a long time and who generally resisted or at least did not like changes to their work practices. Another aspect was the voluntary nature of the intervention; had it been imposed or mandated by management then some participants may not have engaged with the activities: 'If it had been imposed by my manager or from HR I would have just said No and would not have had anything to do with it'.

Building the initial self-efficacy and abilities needed. A couple summed up what was particularly challenging about the intervention: 'you don't usually give yourself time to reflect... in daily life you don't tend to focus on that (i.e. meaningfulness)' and 'it's a different way of thinking which I struggled with to start with'. Many found the activities during the first couple of weeks difficult, and this was, in part, due to them finding the term meaningfulness 'difficult to define'. However, they also highlighted that related concepts that were more commonly understood such as 'well-being', 'motivation', or 'satisfaction' were too generic and did not really fit. Therefore, they would have benefited from some more guidance on how to reflect upon what was meaningful, and how to best set goals which were meaningful. Some described how they 'got into' the activities after a couple of weeks by connecting them much more with their day-to-day work objectives, activities and schedules. 
Sustaining motivation in meaningfulness activities. It was acknowledged by most that a lot of effort was needed to complete the activities each week in part because the activities required a different way of thinking and reflecting than they were used to. Many highlighted that weekly activities may not be the most useful and proposed that longer periods, such as a month, between goals might have enabled richer objectives to have been identified which had more intrinsic meaning. Therefore, there is a need to consider how best to sustain motivation in 'meaningfulness' activities over a period of time. For some, focusing on their internal satisfaction and motive to 'do things that are positive to me' was helpful, whereas others focused on more tangible project/work tasks and outcomes as they help 'check, reflect, and change course if necessary'. Some also suggested that regular structured meetings with informal 'buddies' would be useful in sustaining motivation and ensuring that ideas and goals for creating meaningful impact could be strengthened.

\section{Issues at the meso-level}

Team climate and intergroup relations. It was acknowledged that facilitating meaningfulness could also be focused on within the workgroup: 'you could work on getting the team to develop meaning within the team - goals and a shared mentality of what matters'. This collaborative process of defining and co-creating 'what matters' as a group, and supporting one another's positive contributions would, the participants suggested, lead to the snowballing and 'cultural shift' towards team-based meaningfulness, which some argued would be more impactful as benefits would more likely be 'reflected in (organizationally desired) outputs'. However, some negative aspects were also outlined. Frictions and differences in status/influence between workgroups could lead to value judgements being made, and as such this would need to be addressed within an intervention: 'There can be a perception by certain groups that what we do over here is less meaningful... because what they're doing is the important work'. Moreover, one participant also discussed how negative 
climates and dynamics within their own department was an issue for their overall experience of meaningfulness: 'our team are constantly shouting at each other...it's a really unpleasant environment'. However, this participant, through engaging with the weekly meaningfulness activities, felt empowered to challenge this negative climate to facilitate their own sense of meaningfulness and to improve the social environment: 'This meaningfulness thing is very interesting because it's about trying to figure out what remedial action I can put in place'.

The role of managers in facilitating meaningfulness. One particular role for the line manager discussed by participants was to provide their direct reports with the time, space, and resources necessary to reflect upon meaningfulness; and to utilize one-to-one discussions in a way that focuses not just on performance but also on aspects of meaningfulness and wellbeing: 'if the person raised a concern, or an issue pertaining to the team arose clearly from the meetings, that issue could be seen as a priority for staff morale, or a way to bring in improvements and changes that everyone had the opportunity to contribute to'. Another aspect discussed was the need to get managers across departments together to discuss what is meaningful to the organization and how they best articulate and facilitate that understanding within their teams: 'you want the managers to get together and take a step back and think about what do we actually do as a group, department and organization'.

Utilizing social influence and change agents to facilitate buy-in and involvement. Participants did not wish for such an initiative to be forced onto their colleagues and, despite identifying the benefits of participating, some were hesitant in feeling able to clearly articulate these to encourage others' buy-in. There was recognition that good 'spin' in the organisation to encourage people to be meaningful would be useful and it was widely agreed that a 'soft' managerial approach would work best. This could be maximized through what one participant coined as 'quiet evangelizing', i.e. getting those who have social influence within workgroups to 'sell' and generate enthusiasm to their colleagues and managers: 'it's like 
converting to a religion in a way...it (meaningfulness) needs to be sold in the right way'. Another avenue discussed was focusing the intervention first on those who are at junior to middle grades within the organization who are on promotional pathways might be useful: 'they're energized and very driven... then almost like osmosis you can build it up from there (because) as they go up the ranks in the business they can then use their power and influence'. A few others discussed the importance of a top-down approach where senior managers take the lead on initiating 'meaningful change': 'without those in charge leading the way there is no way for the rest of us to make changes to the way we work'.

Harnessing existing HRM strategies, systems, and processes. Embedding meaningfulness interventions within existing operational HRM practices was highlighted, by most, as important: 'It's about getting it built into the culture and processes in a subtle way'. For example, some discussed how developing existing performance reviews, personal/career development programmes, and internal social events in ways that incorporate meaningfulness activities could be useful: 'It's about putting it within the context'. In particular, the meaningfulness activities had made many participants think about their careers and so aligning developmental as well as performance strategies might be useful. However, some participants, across all the organizations, were critical of established HRM interventions and a concern was raised about explicitly branding anything as a meaningfulness initiative: 'the danger is...it could just fade out. So, it's finding a way to sneak it in and it not become a tick in the box'. To mitigate against this, a few highlighted the importance of goal setting that ensures individuals and managers are all responsible; were meaningfulness to be adopted as a strategic HRM principle then responsibility for this approach may be more readily distributed. Although the HRM functions within the participating organizations seemed interested in doing more on meaningfulness, they were not particularly willing, in reality, to do more than changing some minor elements of existing HRM practices and tools after the 
study was completed, such as adapting engagement surveys, and some core questions within appraisal/development conversation frameworks. Therefore, we are cognizant not to argue that adoption of meaningfulness practices within every HRM function would be feasible.

\section{Issues at the macro-level}

The wider socio-political and economic environment. During the main intervention period within Engineering Co (between April and June 2016) the EU Referendum took place in the UK. The weeks leading up to, and after, the Brexit result had significantly negatively impacted a number of participants' ability to experience meaningfulness in their work during this time: 'last week it was incredibly difficult because of the Referendum result and so everything just seemed meaningless anyway... I wasn't my usual working self'. Given that Engineering Co is a multinational company with its UK branch heavily involved with European counterparts, the Brexit vote impacted on how some employees felt about their potential futures: 'It's a quite distracting situation. Especially when it is felt that the result will have a considerable upset for the company'. An aspect which may have had some influence on the meaningfulness intervention for Gov Co participants was the prevalent ideology within Central Government 'to do more with less'. This was a core concern expressed by a few participants in Gov Co as this created pressure to react quickly to urgent priorities, which placed limits on reflecting and acting upon meaningfulness. Participants from Financial Co expressed that national financial regulation processes did place some boundaries on the extent to which they could organize and craft their jobs in ways that would enable greater meaningfulness, for example in determining quality assurance processes.

\section{Discussion}

Through utilizing a field intervention research design, this study sought to better understand how meaningfulness can be facilitated within the workplace through two core objectives. The 
first focused on examining the psychological effects of the meaningfulness intervention whereby multilevel analyses found that the meaningfulness intervention, relative to the waitlist control group, significantly increased levels of meaningfulness, employee engagement, and personal initiative. The second objective aimed to identify key contextual issues surrounding the meaningfulness intervention, and through thematic analysis of qualitative data from the intervention participants found eight key issues spanning micro, meso, and macro levels. Taken together, the study shows the potential of meaningfulness interventions for enhancing employee engagement and associated behavioral outcomes within the HRM field, yet also highlights that implementing such interventions is not straightforward.

\section{Theoretical implications}

Overall, the study indicates that meaningfulness interventions may 'broaden' the perceived opportunities that enable engagement to occur and trigger volitional motivational processes that promote the capabilities and capacity for enacting personal initiative (Barrick et al.,

2013; Fletcher et al., 2018; Soane et al., 2013). Moreover, we further advance a multidimensional conceptual view of meaningfulness that encompasses meaningfulness in work as well as meaningfulness at work (Pratt \& Ashforth, 2003; Saks, 2011). However, the effects of the meaningfulness intervention must be considered alongside contextual factors that shape the ways in which the above effects can be realized (Nielsen \& Abilgaard, 2013). We therefore focus the rest of the discussion on two 'process' elements that should be considered within theoretical models of meaningfulness.

First, the effects of a meaningfulness intervention may not involve a universally positive affective process that is specific to the work context, and instead may involve other, more temporally and socially situated, processes. In particular, meaningfulness activities can be challenging and emotionally demanding, whereby reflective, social, and goal setting processes help those activities become intrinsically interesting and psychologically 
rewarding. Moreover, broader socio-political and economic events may also influence these processes and indicates that meaningfulness within the context of work is interconnected with one's wider sense of self, life purpose, and social identity. This links with Bailey and Madden's (2017) findings that meaningfulness tends to arise in challenging circumstances where there is a need to overcome complex problems, and with other organizational intervention research that points to the issue that many employees may not be 'ready' for the intervention (Nielsen et al., 2010). Therefore, theories that are applied to understanding the effects of meaningfulness should consider the importance of social/symbolic relevancy and temporality, particularly the way in which meaningfulness 'emerges from an appreciative or reflective act in which the significance of the moment is perceived within a wider timescape' (Bailey \& Madden, 2017, p.13).

Second, a core concern reflected in our study relates to the 'management' of meaningfulness and how meaningfulness interventions would need to be undertaken with authenticity and integrity (Bailey et al., 2017; Lips-Wiersma \& Morris, 2009), such that it aligns with a 'softer' approach to HRM and employee engagement (Jenkins \& Delbridge, 2013). However, as findings suggest, facilitating meaningfulness in the most authentic way may be difficult for HR managers to achieve. This corresponds with prior research on employee engagement by Arrowsmith and Parker (2013, p.2707) that indicates that "HR requires high-level competencies if it is to design, sell and implement significant change proposals relating to [employee engagement]". This raises the tension between management and employee interests and so it would therefore be useful to consider the neopluralism of employment relations (Arrowsmith \& Parker, 2013) and the role of managers in actively shaping the design and implementation of organizational interventions (Nielsen, 2013). For example, future research could examine how HR as well as line managers can resolve 
conflicts to align employees with what is meaningful to the organization with the need to appreciate and encourage each individual's own sense of what is meaningful to them.

\section{Practical implications}

This study suggests that meaningfulness interventions could be adapted to fit within a broader developmental approach such that it could form an essential part of management development and employee-manager conversations around learning and career development. For example, meaningfulness could be utilized to discuss how performance could further be rewarded through goals, at the micro- and meso-levels, that create meaningful impact. Therefore, it could enable practitioners to think more creatively about their engagement strategies in a way that provides employees with greater voice and involvement. However, the study also underscores the difficulties with who owns and manages the interventions as well as how meaningfulness, as a concept, is communicated in ways that align with the existing organization's culture and which would not appear mandated or forced upon people

to 'fit in'. Lastly, the findings highlight the role of managers in building meaningfulness and encouraging proactive, meaningful change within the organization, whilst also being cognizant of the different identities and tensions that exist.

\section{Limitations and suggestions for future research}

Although the study adopted a field intervention research design, there are a few limitations that should be considered. First, a relatively short timeframe was used for the intervention and the follow-up measures. Therefore, future intervention studies should consider how best to maximize the resources available, particularly to strengthen the longitudinal component of the study. Second, the voluntary nature of the recruitment strategy means there may have been sampling selection biases even though there was some level of random allocation of condition. Moreover, although the extent of missing data for T2 outcomes was not an issue, it 
was higher than expected for the T3 outcome of personal initiative. Future research should consider how best to recruit and retain a wider range of participants given the pragmatic reality of conducting field experiments. Lastly, the interventions were conducted within three UK organizations with small samples, albeit from different sectors and locations. Additional research should be conducted with larger samples across a wider range of settings and should also examine how interventions need to be adapted across different cultural contexts.

Relatedly, consideration on how best to adapt the intervention as well as terminology used across differing educational backgrounds and employee groups would be useful as focusing on more abstract concepts may not suit everyone. Therefore, contextualizing interventions to everyday language within the organization would be important as well as adapting more towards 'classic' antecedents of meaningfulness, such as increasing variety and control, in contexts where work design interventions would be appropriate and likely to be effective.

\section{Conclusion}

The current study extends the practical application of meaningful work research by adopting a field intervention research design and reveals how a meaningfulness initiative could be utilized by HRM practitioners as a specific form of engagement intervention. Moreover, understanding participants' accounts provided insight into how meaningfulness interventions could be developed and adapted to fit better within the organizational context. Overall, the concept of meaningfulness provides promising potential for future collaboration between HRM scholars and practitioners that may help develop more employee-centric approaches to engaging employees.

\section{References}

Abildgaard, J. S., Saksvik, P. Ø., \& Nielsen, K. (2016). How to measure the intervention process? An assessment of qualitative and quantitative approaches to data collection 
in the process evaluation of organizational interventions. Frontiers in Psychology, 7, 1380.

Allan, B. A., Duffy, R. D., \& Collisson, B. (2018). Helping others increases meaningful work: Evidence from three experiments. Journal of Counseling Psychology, 65(2), $155-165$.

Arrowsmith, J., \& Parker, J. (2013). The meaning of 'employee engagement' for the values and roles of the HRM function. The International Journal of Human Resource Management, 24(14), 2692-2712.

Bailey, C., \& Madden, A. (2017). Time reclaimed: temporality and the experience of meaningful work. Work, Employment \& Society, 31(1), 3-18.

Bailey, C., Madden, A., Alfes, K., Shantz, A., \& Soane, E. (2017). The mismanaged soul: Existential labor and the erosion of meaningful work. Human Resource Management Review, 27(3), 416-430.

Bailey, C., Yeoman, R., Madden, A., Thompson, M., \& Kerridge, G. (2018). A review of the empirical literature on meaningful work: Progress and research agenda. Human Resource Development Review, online first publication. doi: $10.1177 / 1534484318804653$

Barrick, M. R., Mount, M. K., \& Li, N. (2013). The theory of purposeful work behavior: The role of personality, higher-order goals, and job characteristics. Academy of Management Review, 38(1), 132-153.

Braun, V., \& Clarke, V. (2006). Using thematic analysis in psychology. Qualitative Research in Psychology, 3(2), 77-101. 
Chalofsky, N., \& Krishna, V. (2009). Meaningfulness, commitment, and engagement: The intersection of a deeper level of intrinsic motivation. Advances in Developing Human Resources, 11(2), 189-203.

Chang, C. H., Ferris, D. L., Johnson, R. E., Rosen, C. C., \& Tan, J. A. (2012). Core selfevaluations: A review and evaluation of the literature. Journal of Management, 38(1), 81-128.

Cohen-Meitar, R., Carmeli, A., \& Waldman, D. A. (2009). Linking meaningfulness in the workplace to employee creativity: The intervening role of organizational identification and positive psychological experiences. Creativity Research Journal, 21(4), 361-375.

Costantini, A., De Paola, F., Ceschi, A., Sartori, R., Meneghini, A. M., \& Di Fabio, A. (2017). Work engagement and psychological capital in the Italian public administration: A new resource-based intervention programme. SA Journal of Industrial Psychology, 43(1), 1-11.

Dempsey, S. E., \& Sanders, M. L. (2010). Meaningful work? Nonprofit marketization and work/life imbalance in popular autobiographies of social entrepreneurship. Organization, 17(4), 437-459.

Fletcher, L. (2016). How can personal development lead to increased engagement? The roles of meaningfulness and perceived line manager relations. The International Journal of Human Resource Management. Online first. doi: 10.1080/09585192.2016.1184177

Fletcher, L., Bailey, C., \& Gilman, M. (2018). Fluctuating levels of personal role engagement within the working day: A multilevel study. Human Resource Management Journal, $28(1), 128-147$. 
Frese, M., Fay, D., Hilburger, T., Leng, K., \& Tag, A. (1997). The concept of personal initiative: Operationalization, reliability and validity in two German samples. Journal of Occupational and Organizational Psychology, 70(2), 139-161.

Glazer, S., Kozusznik, M.W., Meyers, J.H., \& Ganai, O. (2014). Meaningfulness as a resource to mitigate work stress. In S. Leka, \& R.R. Sinclair (Eds.), Contemporary Occupational Health Psychology: Global Perspectives on Research and Practice, Volume 3 (pp.114-130). Chichester, UK: John Wiley \& Sons.

Hackman, R., \& Oldham, G. R. (1976). Motivation through the design of work: Test of a theory. Organizational Behavior and Human Experience, 16(2), 250-279.

Hakanen, J. J., Perhoniemi, R., \& Toppinen-Tanner, S. (2008). Positive gain spirals at work: From job resources to work engagement, personal initiative and work-unit innovativeness. Journal of Vocational Behavior, 73(1), 78-91.

Hobfoll, S. E. (2011). Conservation of resource caravans and engaged settings. Journal of Occupational and Organizational Psychology, 84(1), 116-122.

Jenkins, S., \& Delbridge, R. (2013). Context matters: examining "soft" and "hard" approaches to employee engagement in two workplaces. The International Journal of Human Resource Management, 24(14), 2670-2691.

Johns, G. (2006). The essential impact of context on organizational behavior. Academy of Management Review, 31(2), 386-408.

Judge, T. A., Erez, A., Bono, J. E., \& Thoresen, C. J. (2003). The core self-evaluations scale: Development of a measure. Personnel Psychology, 56(2), 303-331.

Kahn, W. A. (1990). Psychological conditions of personal engagement and disengagement at work. Academy of Management Journal, 33(4), 692-724. 
Kahn, W. A., \& Heaphy, E. D. (2014). Relational contexts of personal engagement at work. In C. Truss, K. Alfes, R. Delbridge, A. Shantz, \& E. C. Soane (Eds.), Employee Engagement in Theory and Practice (pp. 82-96). London: Routledge.

Katz, D., \& Kahn, R. L. (1978). The Social Psychology of Organizations. New York: Wiley.

Lips-Wiersma, M., \& Morris, L. (2009). Discriminating between 'meaningful work' and the 'management of meaning'. Journal of Business Ethics, 88(3), 491-511.

Lischetzke, T., Reis, D., \& Arndt, C. (2015). Data-analytic strategies for examining the effectiveness of daily interventions. Journal of Occupational and Organizational Psychology, 88(3), 587-622.

Lysova, E. I., Allan, B. A., Dik, B. J., Duffy, R. D., \& Steger, M. F. (2018). Fostering meaningful work in organizations: A multi-level review and integration. Journal of Vocational Behavior. Online first publication. doi: 10.1016/j.jvb.2018.07.004

May, D. R., Gilson, R. L., \& Harter, L. M. (2004). The psychological conditions of meaningfulness, safety and availability and the engagement of the human spirit at work. Journal of Occupational and Organizational Psychology, 77(1), 11-37.

Nielsen, K. (2013). How can we make organizational interventions work? Employees and line managers as actively crafting interventions. Human Relations, 66(8), 1029-1050.

Nielsen, K., \& Abildgaard, J. S. (2013). Organizational interventions: A research-based framework for the evaluation of both process and effects. Work \& Stress, 27(3), 278297.

Nielsen, K., \& Randall, R. (2013). Opening the black box: Presenting a model for evaluating organizational-level interventions. European Journal of Work and Organizational Psychology, 22(5), 601-617. 
Nielsen, T., Taris, T.W., \& Cox, T. (2010). The future of organizational interventions: Addressing the challenges of today's organizations. Work \& Stress, 24(3), 219-233.

Pratt, M. G., \& Ashforth, B. E. (2003). Fostering meaningfulness in working and at work. In K.S. Cameron, J.E. Dutton, \& R.E. Quinn (Eds.), Positive Organizational Scholarship: Foundations of a New Discipline (pp. 309-327). San Francisco, CA: Berrett-Koehler Publishers.

Preacher, K. J., Curran, P. J., \& Bauer, D. J. (2006). Computational tools for probing interactions in multiple linear regression, multilevel modeling, and latent curve analysis. Journal of Educational and Behavioral Statistics, 31(4), 437-448.

Rashbash, J., Steele, F., Browne, W., \& Goldstein, H. (2015). A user's guide to MLwiN Version 2.32. Bristol, UK: Centre for Multilevel Modelling, University of Bristol.

Rosso, B. D., Dekas, K. H. and Wrzesniewski, A. (2010). On the meaning of work: A theoretical integration and review. Research in Organizational Behavior, 30, 91-127.

Saks, A.M. (2011). Workplace spirituality and employee engagement. Journal of Management, Spirituality and Religion, 8, 317-340.

Shuck, B., \& Rose, K. (2013). Reframing employee engagement within the context of meaning and purpose: Implications for HRD. Advances in Developing Human Resources, 15(4), 341-355.

Soane, E., Shantz, A., Alfes, K., Truss, C., Rees, C., \& Gatenby, M. (2013). The association of meaningfulness, well-being, and engagement with absenteeism: A moderated mediation model. Human Resource Management, 52(3), 441-456.

Soane, E., Truss, C., Alfes, K., Shantz, A., Rees, C., \& Gatenby, M. (2012). Development and application of a new measure of employee engagement: The ISA Engagement Scale. Human Resource Development International, 15(5), 529-547. 
Tajfel, H., \& Turner, J. C. (1979). An integrative theory of intergroup conflict. In W.G. Austin, \& S. Worchel (Eds.), The Social Psychology of Intergroup Relations (pp.3347). Monterey, CA: Brooks-Cole.

Thomas, K. W., \& Velthouse, B. A. (1990). Cognitive elements of empowerment: An "interpretive" model of intrinsic task motivation. Academy of Management Review, 15(4), 666-681.

Thory, K. (2016). Developing meaningfulness at work through emotional intelligence training. International Journal of Training and Development, 20(1), 58-77.

Truss, C., Shantz, A., Soane, E., Alfes, K., \& Delbridge, R. (2013). Employee engagement, organisational performance and individual well-being: exploring the evidence, developing the theory. The International Journal of Human Resource Management, 24(14), 2657-2669.

Vigoda-Gadot, E., Eldor, L., \& Schohat, L. M. (2013). Engage them to public service: Conceptualization and empirical examination of employee engagement in public administration. The American Review of Public Administration, 43(5), 518-538.

Voegtlin, C., Boehm, S. A., \& Bruch, H. (2015). How to empower employees: using training to enhance work units' collective empowerment. International Journal of Manpower, 36(3), 354-373.

Wood, S., \& Ogbonnaya, C. (2016). High-involvement management, economic recession, well-being, and organizational performance. Journal of Management, online first publication. doi: 10.1177/0149206316659111.

Yeoman, R. (2014). Conceptualising meaningful work as a fundamental human need. Journal of Business Ethics, 125(2), 235-251. 
Yin, R.K. (2009). Case Study Research: Design and Methods (4th ed.). Thousand Oaks, CA: Sage Publications. 
Table 1. Multilevel CFA on the five dependent variables

\begin{tabular}{llllll}
\hline & $\begin{array}{l}\text { Chi-Square } \\
\chi^{2}(d f) / \Delta \chi^{2}\end{array}$ & $\chi^{2} /$ df ratio & RMSEA & CFI & $\begin{array}{l}\text { SRMR } \\
\text { within/between }\end{array}$ \\
\hline 5 factor model & $797.26(530) / 66.86^{* * *}$ & 1.50 & 0.06 & 0.89 & $0.10 / 0.14$ \\
Alternative 4 factor model & $864.12(538) / 61.12^{* * * *}$ & 1.61 & 0.06 & 0.86 & $0.17 / 0.46$ \\
Alternative 3 factor model & $925.24(544) / 226.81^{* * *}$ & 1.70 & 0.07 & 0.84 & $0.13 / 0.43$ \\
Alternative 2 factor model & $1152.05(548) / 158.68^{* * * *}$ & 2.10 & 0.09 & 0.74 & $0.15 / 0.21$ \\
Alternative 1 factor model & $1310.73(550)$ & 2.38 & 0.10 & 0.67 & $0.18 / 0.35$ \\
\hline
\end{tabular}

*** $\mathrm{p}<.001$. Note: 5 factor model (meaningfulness in work, meaningfulness at work, job engagement, organization engagement, personal initiative), 4 factor model (meaningfulness in work/meaningfulness at work, job engagement, organization engagement, personal initiative), 3 factor model (meaningfulness in work/meaningfulness at work, job engagement/organization engagement, personal initiative), 2 factor model (meaningfulness in work/meaningfulness at work/job engagement/organization engagement, personal initiative), 1 factor model (meaningfulness in work/meaningfulness at work/job engagement/ organization engagement/personal initiative) 
Table 2. Results of multilevel analyses testing the effects of the meaningfulness intervention

\begin{tabular}{|c|c|c|c|c|c|c|c|c|c|c|}
\hline \multirow{3}{*}{ Parameter } & \multicolumn{2}{|c|}{ Meaningfulness in work } & \multicolumn{2}{|c|}{ Meaningfulness at work } & \multicolumn{2}{|c|}{ Job engagement } & \multicolumn{2}{|c|}{ Organization engagement } & \multicolumn{2}{|c|}{ Personal initiative } \\
\hline & Model 1 & Model 2 & Model 1 & Model 2 & Model 1 & Model 2 & Model 1 & Model 2 & Model 1 & Model 2 \\
\hline & Est. (SE) & Est. (SE) & Est. (SE) & Est. (SE) & Est. (SE) & Est. (SE) & Est. (SE) & Est. (SE) & Est. (SE) & Est. (SE) \\
\hline \multirow{2}{*}{ Intercept } & 4.96 & 5.06 & 5.12 & 5.31 & 5.25 & 5.32 & 3.80 & 3.88 & 5.18 & 5.25 \\
\hline & $(0.20)^{* * *}$ & $(0.20)^{* * *}$ & $(0.19)^{* * *}$ & $(0.19)^{* * *}$ & $(0.15)^{* * *}$ & $(0.16)^{* * *}$ & $(0.24)^{* * *}$ & $(0.24)^{* * *}$ & $(0.17)^{* * *}$ & $(0.17)^{* * *}$ \\
\hline \multirow{2}{*}{ Time } & 0.20 & -0.01 & -0.02 & -0.41 & 0.03 & -0.10 & 0.15 & -0.12 & 0.08 & -0.22 \\
\hline & $(0.10)^{*}$ & $(0.15)$ & $(0.12)$ & $(0.17)^{*}$ & $(0.08)$ & $(0.11)$ & $(0.12)$ & $(0.18)$ & $(0.08)$ & $(0.13)^{\mathrm{x}}$ \\
\hline \multirow{2}{*}{ Financial Co } & -0.22 & -0.23 & -0.26 & -0.27 & -0.44 & -0.44 & -0.30 & -0.31 & -0.31 & -0.32 \\
\hline & $(0.22)$ & $(0.22)$ & $(0.20)$ & $(0.20)$ & $(0.17)^{* *}$ & $(0.17)^{* *}$ & $(0.27)$ & $(0.27)$ & $(0.20)$ & $(0.20)$ \\
\hline \multirow{2}{*}{ Public Co } & 0.45 & 0.45 & 0.52 & 0.53 & 0.32 & 0.32 & 0.70 & 0.71 & 0.50 & 0.50 \\
\hline & $(0.22)^{*}$ & $(0.22)^{*}$ & $(0.20)^{*}$ & $(0.20)^{* *}$ & $(0.17)^{\mathrm{t}}$ & $(0.17)^{\mathrm{t}}$ & $(0.28)^{* *}$ & $(0.28)^{* *}$ & $(0.20)^{*}$ & $(0.20)^{*}$ \\
\hline \multirow{2}{*}{ CSE } & 0.50 & 0.50 & 0.50 & 0.49 & 0.50 & 0.50 & 0.43 & 0.43 & 0.32 & 0.31 \\
\hline & $(0.09)^{* * *}$ & $(0.09)^{* * * *}$ & $(0.09)^{* * *}$ & $(0.09)^{* * *}$ & $(0.07)^{* * *}$ & $(0.07)^{* * *}$ & $(0.12)^{* * *}$ & $(0.12)^{* * *}$ & $(0.09)^{* * *}$ & $(0.09)^{* * *}$ \\
\hline \multirow{2}{*}{ Condition } & 0.17 & -0.02 & 0.11 & -0.23 & 0.16 & 0.05 & -0.06 & -0.20 & -0.06 & -0.18 \\
\hline & $(0.18)$ & $(0.21)$ & $(0.17)$ & $(0.20)$ & $(0.14)$ & $(0.16)$ & $(0.22)$ & $(0.24)$ & $(0.16)$ & $(0.17)$ \\
\hline \multirow{2}{*}{ Time $*$ Condition } & & 0.39 & & 0.70 & & 0.24 & & 0.47 & & 0.47 \\
\hline & & $(0.20)^{*}$ & & $(0.23)^{* *}$ & & $(0.14)^{\mathrm{t}}$ & & $(0.24)^{*}$ & & $(0.16)^{* *}$ \\
\hline Time slope variance & 0.77 & 0.73 & 1.12 & 0.99 & 0.43 & 0.41 & 1.12 & 1.06 & 0.46 & 0.40 \\
\hline$-2 * \log$ & 379.64 & 375.04 & 342.01 & 8.57 & 295.46 & 291.93 & 440.50 & 436.88 & 302.49 & 294.77 \\
\hline
\end{tabular}

Note: For all dependent variables, except for personal initiative, analyses based on 153 measurements clustered within 80 individuals. For personal initiative, analyses based

on 143 measurements clustered within 80 individuals. Time was coded 0 - before study, 1 - after study; Financial Co and Public Co were coded 0 - no, 1 - yes; CSE was grand-mean centred; and condition was coded 0 - control, 1 - intervention. $\Delta-2 * \log$ for model 1 is based on null random intercept model. ${ }^{\mathrm{f}} p<.10, * p<.05, * * p<.01, * * *$ $p<.001$ 
Table 3. Simple slope results for each dependent variable and study condition

\begin{tabular}{|c|c|c|c|c|c|c|c|c|}
\hline \multirow[b]{2}{*}{ Dependent variable } & \multicolumn{4}{|c|}{ Wait-list Control Group } & \multicolumn{4}{|c|}{ Meaningfulness Intervention Group } \\
\hline & $\begin{array}{l}\text { Pre- } \\
\text { study } \\
\text { predicted } \\
y \text { value }\end{array}$ & $\begin{array}{l}\text { Post- } \\
\text { study } \\
\text { predicted } \\
y \text { value }\end{array}$ & $\begin{array}{l}\text { Simple } \\
\text { slope } \\
b(S E)\end{array}$ & $\begin{array}{l}\text { Simple } \\
\text { slope } \\
z\end{array}$ & $\begin{array}{l}\text { Pre- } \\
\text { study } \\
\text { predicted } \\
y \text { value }\end{array}$ & $\begin{array}{l}\text { Post-study } \\
\text { predicted } \\
y \text { value }\end{array}$ & $\begin{array}{l}\text { Simple } \\
\text { slope } \\
b(S E)\end{array}$ & $\begin{array}{l}\text { Simple } \\
\text { slope } \\
z\end{array}$ \\
\hline $\begin{array}{l}\text { Meaningfulness in } \\
\text { work }\end{array}$ & 5.06 & 5.05 & $\begin{array}{l}-0.01 \\
(0.15)\end{array}$ & 0.09 & 5.04 & 5.41 & $\begin{array}{l}0.37 \\
(0.13)\end{array}$ & $2.75^{* *}$ \\
\hline $\begin{array}{l}\text { Meaningfulness } a t \\
\text { work }\end{array}$ & 5.31 & 4.91 & $\begin{array}{l}-0.41 \\
(0.17)\end{array}$ & $2.36^{*}$ & 5.08 & 5.37 & $\begin{array}{l}0.29 \\
(0.15)\end{array}$ & $1.89^{\mathrm{a}}$ \\
\hline Job engagement & 5.32 & 5.23 & $\begin{array}{l}-0.10 \\
(0.11)\end{array}$ & 0.89 & 5.36 & 5.51 & $\begin{array}{l}0.15 \\
(0.09)\end{array}$ & $1.65^{\mathrm{a}}$ \\
\hline $\begin{array}{l}\text { Organization } \\
\text { engagement }\end{array}$ & 3.88 & 3.76 & $\begin{array}{l}-0.12 \\
(0.18)\end{array}$ & 0.64 & 3.68 & 4.03 & $\begin{array}{l}0.35 \\
(0.16)\end{array}$ & $2.19 *$ \\
\hline Personal initiative & 5.24 & 5.04 & $\begin{array}{l}-0.22 \\
(0.13)\end{array}$ & $1.66^{\mathrm{a}}$ & 5.08 & 5.34 & $\begin{array}{l}0.26 \\
(0.10)\end{array}$ & $2.56 * *$ \\
\hline
\end{tabular}

${ }^{\mathrm{a}} \mathrm{p}<.10, * \mathrm{p}<.05, * * \mathrm{p}<.01, * * * \mathrm{p}<.001$ 


\section{Appendix A: Focus Group Interview Guide}

1. What have you learnt so far about your own sense of meaningfulness within the workplace?

2. What benefits do you think this type of initiative would have on you - in short/medium/long term?

3. What benefits do you think this type of initiative would have on your department/organisation - in short/medium/long term?

4. What particular drawbacks are there about doing this type of initiative?

5. What would you change, strengthen or develop about this particular initiative to better facilitate your sense of meaningfulness?

6. How can your organisation better embed and facilitate meaningfulness?

7. Overall, to what extent do you think meaningfulness should be incorporated within an overall workplace strategy? 